Annals of Pure and Applied Mathematics

Vol. 15, No. 1, 2017, 41-49

ISSN: 2279-087X (P), 2279-0888(online)

Published on 11 December 2017

www.researchmathsci.org

DOI: http://dx.doi.org/10.22457/apam.v15n1a4

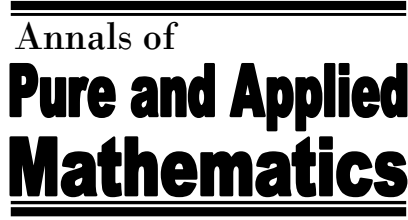

\title{
Inventory Control in Retrial Service Facility System - Semi Markov Decision Process
}

\author{
S.Krishnakumar ${ }^{1}$ and C.Elango ${ }^{2}$ \\ Research Department of Mathematical Sciences \\ Cardamom Planters' Association College \\ Bodinayakanur - 625 513, Tamil Nadu, India \\ ${ }^{1}$ Corresponding Author. E-mail: ${ }^{1}$ krishmathew@ gmail.com, \\ Received 2 November 2017; accepted 5 December 2017
}

\begin{abstract}
This paper treats the optimal controlling of the inventory replenishment in retrial service facility system maintaining inventory for service. Arrival of demands to the system is assumed as Poisson and service times are assumed to follows an exponential distribution. Here, the customers are not allowed to form a queue. A customer who sees the server busy joins the orbit and reattempts the system with exponential distribution time. For the given values of maximum inventory and reorder level, we determine the optimal ordering policy at various instants of time. The system is formulated as a SemiMarkov Decision Process and the optimum service rates to be employed is found using linear programming method so that the long-run expected cost rate is minimized. Numerical examples are provided to illustrate the model.
\end{abstract}

Keywords: Single server, service facility, retrial queue, inventory system, semi-markov decision process

AMS Mathematics Subject Classification (2010): 60K25, 60K20

\section{Introduction}

Queuing systems with retrials, in which customers repeat attempts to obtain service, was originally a topic of telecommunications research. More recently, these systems have served as models for particular computer networks, which may explain the current level of activity on the subject. As an example, the "customers" of this queue could be a network of computers attempting to access the same database, which may only be used by one customer at a time.

In last two decades, many researchers in the field of retrial queuing system contributed many results. For example, Elcan [8], Arivudainambi et al. [1], Dragieva [6], Dudin et al. [7] and Artalejo et al. [3,5] discussed a single server retrial queue with returning customers examined by balking or Bernoulli vacations and derived the analysis part and solution technique using Matrix method or generating function or Truncation method using level dependent quasi-birth-and-death process (LDQBD).

Paul et al. [13] and Krishnamoorthy et al. [11, 12] analyzed a continuous review inventory system at a service facility and retrial of customers. In all these systems, arrival of customers form a Poisson process and service times are exponentially distributed. 


\section{S.Krishnakumar and C.Elango}

They investigate the systems to compute performance measures and construct suitable cost functions.

The main contribution of this article is to derive the optimum control rule for the inventory replenishment process in retrial service facility system maintaining inventory for service. We consider a service facility system and the orbit with finite waiting space. For the given values of maximum waiting space, maximum inventory, reorder level s and lead times, the system is formulated as a Semi-Markov Decision Process and the optimum inventory policy to be employed is obtained using linear programming method so that the long - run expected cost rate is minimized.

The rest of the paper is organized as follows. Preliminary concepts of retrial queues is given in section 1. A brief account of Markov process with continuous time space is described in section 2. We provide a formulation of our Semi - Markov Decision model in the next section 3. In section 4 , we present a procedure to implement long-run expected cost rate criteria to get the optimal vales of the system parameters.

\section{Preliminaries}

In this paper, we assume the following: A customer arrives to the system according to a Poisson process with rate $\lambda(>0)$. When the server is idle the arriving customer directly enters the server gets service and leaves the system. An arriving customer who finds a server busy is obliged to leave the service area and repeats his request from a virtual space namely orbit. A reattempt made by a customer after a random time for the service from the orbit is called retrial. Customer's retrials for service from an orbit follow an exponential distribution with rate $\delta(>0)$ ). (If there are i customers stay in the orbit the retrial rate is i $\delta$ ).

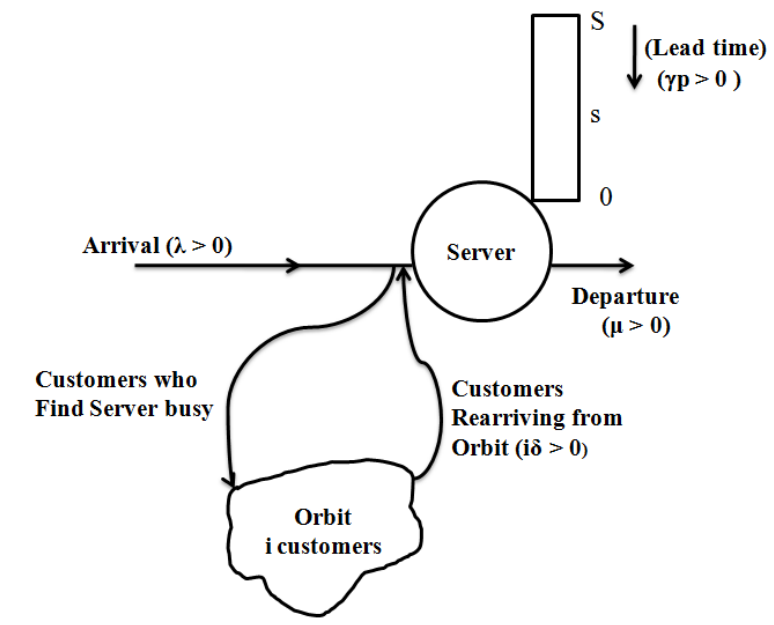

Figure 1: Inventory Control in Retrial Service Facility System

Service times of customers are independent of each other and have a common exponential distribution with parameter $\mu(>0)$. One (unit) of item is served to each customer during service. The capacity of orbit is limited to the maximum of $\mathrm{N}$. The maximum capacity of the inventory is fixed as $\mathrm{S}$. Whenever the inventory level reaches to a prefixed level $\mathrm{s}(0 \leq \mathrm{s}<\mathrm{S})$, an order for $\mathrm{Q}=\mathrm{S}-\mathrm{s}>\mathrm{s}$ items is placed and the lead 


\section{Inventory Control in Retrial Service Facility System- Semi Markov Decision Process}

time follows an exponential distribution with parameter $\gamma$.Supply of items from manufacturer is random with fixed probability say $\mathrm{p}$.

The order filling for the inventory occurs with rate $\gamma p(>0)$ and non - filling the inventory with rate $\gamma(1-p)$ where $p$ denote the probability of supply of order quantity. The size of the order is adjusted at the time of replenishment so that immediately after replenishment the inventory level becomes S. Order decision is made at each level less than or equal to the reorder level s. Whenever the inventory level reaches to zero, the arriving customers enter the orbit, status of the server remains 0 .

\section{Analysis of system}

Let $\mathrm{X}(\mathrm{t}), \mathrm{N}(\mathrm{t})$ and $\mathrm{I}(\mathrm{t})$ denotes the status of the server, number of customers in the orbit and inventory level at time $t$, respectively.

Then $\{(\mathrm{X}(\mathrm{t}), \mathrm{N}(\mathrm{t}), \mathrm{I}(\mathrm{t})): \mathrm{t} \geq 0\}$ is a three dimensional continuous time Markov process with state space $E_{1} \times E_{2} \times E_{3}$, where,

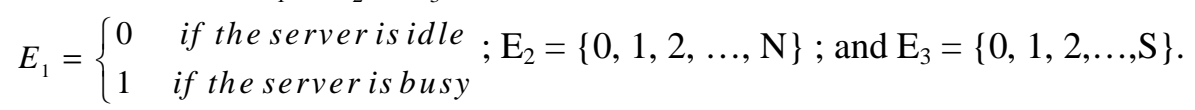

The infinitesimal generator A of the Markov process has entries of the form $\left(a_{(\mathrm{i}, \mathrm{j}, \mathrm{k})}^{(\mathrm{l}, \mathrm{n})}\right)$.

Some of the state transitions are given below:

From state $(0, \mathrm{j}, \mathrm{k})$ only transitions into the following states are possible:

(i) $(1, \mathrm{j}, \mathrm{k})$ with rate $\lambda$ (direct customer arrival).

(ii) $(1, \mathrm{j}-1, \mathrm{k})$ with rate $\mathrm{j} \delta$ (Customer arrival from orbit).

Here, $\mathrm{j}=1,2 \ldots, \mathrm{N}$ and $\mathrm{k}=0,1,2 \ldots, \mathrm{S}$.

From state $(1, \mathrm{j}-1, \mathrm{k})$ only transitions into the following states are possible:

(i) $(1, \mathrm{j}, \mathrm{k})$ with rate $\lambda$ (direct customer arrival).

(ii) $(0, \mathrm{j}-1, \mathrm{k}-1)$ with rate $\mu$ (Service completion).

Here, $\mathrm{j}=1,2 \ldots \mathrm{N}$ and $\mathrm{k}=1,2 \ldots \mathrm{S}$.

From states $(0, j, 0)$ transitions are possible only to the states $(0, j+1,0)$ for $0 \leq \mathrm{j} \leq \mathrm{N}-1$.

\subsection{MDP formulation}

Now, we formulate the MDP by considering the following five components:

Decision epochs: The decision epochs for the system are taken as random points of time say the service completion times.

State space: $E_{1} \times E_{2} \times E_{3}=E$ is considered as the state space, where

$$
E_{1}=\left\{\begin{array}{l}
0 \quad \text { if the server is idle } \\
1 \quad \text { if the server is busy }
\end{array} ; E_{2}=\{0,1,2,, \ldots, \mathrm{N}\} ; \text { and } E_{3}=\{0,1,2, \ldots, \mathrm{S}\}\right.
$$

Action set: The reordering decisions (0- no order;1- order; 2 -compulsory order) taken at each state of the system $(\mathrm{i}, \mathrm{j}, \mathrm{k}) \in \mathrm{E}$ and the replenishment of inventory done at rate $\gamma \mathrm{p}$. The compulsory order for $\mathrm{S}$ items is made when inventory level is zero. Let $\mathrm{A}_{\mathrm{r}}(\mathrm{r}=1,2$, 3 ) denotes the set of possible actions. Where, $A_{1}=\{0\}, A_{2}=\{0,1\}, A_{3}=\{2\}$ and $\mathrm{A}=\mathrm{A}_{1} \cup \mathrm{A}_{2} \cup \mathrm{A}_{3}$.

The set of all possible actions are at $\mathrm{r} \in \mathrm{E}$. 


$$
\begin{gathered}
\text { S.Krishnakumar and C.Elango } \\
A_{r}=\left\{\begin{array}{cc}
\{0\}, & s+1 \leq k \leq S \\
\{0,1\}, & 1 \leq k \leq s \quad \\
\{2\}, & k=0
\end{array} \quad A=\bigcup_{r \in E} A_{r} .\right.
\end{gathered}
$$

Suppose the policy $f$ (sequence of decisions) is defined as a function $f: \mathrm{E} \rightarrow \mathrm{A}$, given by

$$
\begin{aligned}
& f(i, j, k)=\left\{(a):(i, j, k) \in E_{r}, a \in A_{r}, r=1,2,3\right\} \\
& \text { Let } E_{1}=\left\{(i, j, k) \in E^{\prime} / f(i, j, k)=0\right\} . \\
& E_{2}=\left\{(i, j, k) \in E^{\prime} / f(i, j, k)=0 \text { or } 1\right\} \\
& E_{3}=\left\{(i, j, k) \in E^{\prime} / f(i, j, k)=2\right\} .
\end{aligned}
$$

Transition probability: $p_{(i, \mathrm{j}, k)}^{(\mathrm{l}, \mathrm{m}, \mathrm{n})}(a)$ denote the transition probability from state $(\mathrm{i}, \mathrm{j}, \mathrm{k})$ to state $(1, m, n)$ when decision a is made at state $(\mathrm{i}, \mathrm{j}, \mathrm{k})$.

Cost: $\underset{(\mathrm{i}, \mathrm{j}, k)}{C}(a)$ denote the cost occurred in the system when action ' $\mathrm{a}$ ' is taken at state $(\mathrm{i}, \mathrm{j}, \mathrm{k})$.

\subsection{Steady state analysis}

Let $\mathrm{R}$ denote the stationary policy, which is deterministic time invariant and Markovian Policy (MD). From our assumptions it can be seen that $\{(\mathrm{X}(\mathrm{t}), \mathrm{N}(\mathrm{t}), \mathrm{I}(\mathrm{t})): t \geq 0\}$ is denoted as the controlled process $\left\{\left(X^{R}(t), \mathrm{N}^{R}(t), \mathrm{I}^{R}(t)\right): t \geq 0\right\}$ when policy $\mathrm{R}$ is adopted. The above process is completely Ergodic, if every stationary policy gives rise to an irreducible Markov chain. It can be seen that for every stationary policy $f,\left\{\mathrm{X}^{f}, \mathrm{~N}^{f}, I^{f}\right\}$ is completely Ergodic and also the optimal stationary policy $\mathrm{R}^{*}$ exists, because the state and action spaces are finite.

If $d_{t}$ is the Markovian deterministic decision rule, the expected reward satisfies the transition probability relations.

$$
\begin{gathered}
p_{t}\left((1, \mathrm{~m}, \mathrm{n}) \mid(\mathrm{i}, \mathrm{j}, \mathrm{k}), d_{t}(\mathrm{i}, \mathrm{j}, \mathrm{k})\right)=\sum_{a \in A_{s}} p_{t}((1, \mathrm{~m}, \mathrm{n}) \mid(\mathrm{i}, \mathrm{j}, \mathrm{k}), \mathrm{a}) p_{\mathrm{d}_{t}(\mathrm{i}, \mathrm{j}, \mathrm{k})}(a) \text {. } \\
r_{t}(\mathrm{i}, \mathrm{j}, \mathrm{k}), d_{t}(\mathrm{i}, \mathrm{j}, \mathrm{k})=\sum_{a \in A_{s}} r_{t}(\mathrm{i}, \mathrm{j}, \mathrm{k}, \mathrm{a}) p_{\mathrm{d}_{t}(\mathrm{i}, \mathrm{j}, \mathrm{k})}(a) .
\end{gathered}
$$

For Deterministic Markovian Policy $\Pi \in \Pi^{M D}$, where, $\Pi^{M D}$ denotes the space of Deterministic Markovian policy. Under this policy $\Pi_{\text {an action }} a \in A(\mathrm{r})$ is chosen with probability $\Pi_{a}(\mathrm{r})$, whenever the process is in state $k \in E$. Whenever $\Pi_{a}(\mathrm{r})=0 \operatorname{or} 1$, the stationary Markovian policy $\Pi$ reduces to a familiar stationary policy.

Then the controlled process $\left\{\mathrm{X}^{\mathrm{R}}, \mathrm{N}^{\mathrm{R}}, \mathrm{I}^{\mathrm{R}}\right\}$, where, $\mathrm{R}$ is the deterministic Markovian policy is a Markov process. Under the policy $\Pi$, the expected long run total cost rate is given by

$$
C^{\Pi}=h \bar{I}^{\Pi}+c_{1} \bar{w}^{\Pi}+c_{2} \alpha_{a}{ }^{\Pi}+\beta \alpha_{b}{ }^{\Pi} .
$$

where, $\mathrm{h}$-holding cost / unit item / unit time, $\mathrm{c}_{1}$ - waiting cost / customer / unit time, $c_{2}$ - reordering cost / order, $\beta$ - service cost / customer, $\bar{I}^{\Pi}$ - mean inventory level, $\bar{w}^{\Pi}$ - mean waiting time in orbit, $\alpha_{a}^{\Pi}$ - reordering rate, $\alpha_{b}{ }^{\Pi}$ - service completion rate. 
Inventory Control in Retrial Service Facility System-Semi Markov Decision Process

Our objective here is to find an optimal policy $\Pi^{*}$ for which $C^{\Pi^{*}} \leq C^{\Pi}$ for every MD policy in $\Pi^{M D}$

For any fixed MD policy $\Pi \in \Pi^{M D}$ and $(i, \mathrm{j}, \mathrm{k}),(1, \mathrm{~m}, \mathrm{n}) \in E$, define

$P_{i j k}^{\Pi}(1, \mathrm{~m}, \mathrm{n}, \mathrm{t})=P \operatorname{r}\left\{X^{\Pi}(t)=l, \mathrm{~N}^{\Pi}(t)=m, \mathrm{I}^{\Pi}(t)=n \mid \mathrm{X}^{\Pi}(0)=i, \mathrm{~N}^{\Pi}(0)=j, \mathrm{I}^{\Pi}(0)=k\right\}$ $(i, \mathrm{j}, \mathrm{k}),(1, \mathrm{~m}, \mathrm{n}) \in E$.

Now $P_{i j k}^{\pi}(l, m, n, t)$ satisfies the Kolmogorov forward differential equation $P_{k}{ }^{\prime}(\mathrm{t})=\mathrm{P}(\mathrm{t}) \mathrm{A}$, where, A is an infinitesimal generator of the Markov process $\left\{\left(\mathrm{X}^{\pi}(\mathrm{t}), \mathrm{N}^{\pi}(\mathrm{t}), \mathrm{I}^{\pi}(\mathrm{t})\right): \mathrm{t} \geq 0\right\}$.

For each MD policy $\pi$, we get an irreducible Markov chain with the state space $\mathrm{E}$ and actions space $\mathrm{A}$ which are finite,

${ }^{P} \pi(1, \mathrm{~m}, \mathrm{n})=\lim _{t \rightarrow \infty} P_{i j k}^{\pi}(1, \mathrm{~m}, \mathrm{n} ; t)$ exists and is independent of initial state conditions. Now the system of equations obtained can be written as follows:

$$
\begin{aligned}
& \lambda P(0,0, \mathrm{~S})=\gamma p \sum_{k=0}^{s} \mathrm{P}(0,0, \mathrm{k}) \\
& (\lambda+\mathrm{j} \delta) \mathrm{P}(0, \mathrm{j}, \mathrm{S})=\gamma p \sum_{k=0}^{s} \mathrm{P}(0, \mathrm{j}, \mathrm{k}), 1 \leq j \leq N \\
& (\lambda+\mu) \mathrm{P}(1,0, \mathrm{~S})=\lambda P(0,0, \mathrm{~S})+\delta P(0,1, \mathrm{~S})+\gamma p \sum_{k=1}^{s} \mathrm{P}(1,0, \mathrm{k}) \\
& (\lambda+\mu) \mathrm{P}(1, \mathrm{j}, \mathrm{S})=\lambda \sum_{i=0,1} P(\mathrm{i}, \mathrm{j}-\mathrm{i}, \mathrm{S})+(\mathrm{j}+1) \delta P(0, \mathrm{j}+1, \mathrm{~S})+\gamma p \sum_{k=1}^{s} \mathrm{P}(1, \mathrm{j}, \mathrm{k}), 1 \leq j \leq N-1 \\
& \mu \mathrm{P}(1, \mathrm{~N}, \mathrm{~S})=\lambda \sum_{i=0}^{1} P(\mathrm{i}, \mathrm{N}-\mathrm{i}, \mathrm{k})+\gamma p \sum_{k=1}^{s} \mathrm{P}(1, \mathrm{~N}, \mathrm{k}) \\
& \lambda P(0,0, \mathrm{k})=\mu \mathrm{P}(1, \mathrm{j}, \mathrm{k}+1), s+1 \leq k \leq S-1 \\
& (\lambda+\mathrm{j} \delta) \mathrm{P}(0, \mathrm{j}, \mathrm{k})=\mu \mathrm{P}(1, \mathrm{j}, \mathrm{k}+1), 1 \leq \mathrm{j} \leq \mathrm{N}, s+1 \leq k \leq S-1 \\
& (\lambda+\mu) \mathrm{P}(1,0, \mathrm{k})=\lambda \mathrm{P}(0,0, \mathrm{k})+\delta \mathrm{P}(0,1, \mathrm{k}), s+1 \leq k \leq S-1 \\
& (\lambda+\mu) \mathrm{P}(1, \mathrm{j}, \mathrm{k})=\lambda \sum_{i=0}^{1} P(\mathrm{i}, \mathrm{j}-\mathrm{i}, \mathrm{k})+(\mathrm{j}+1) \delta \mathrm{P}(0, \mathrm{j}+1, \mathrm{k}), 1 \leq \mathrm{j} \leq \mathrm{N}-1, s+1 \leq k \leq S-1
\end{aligned}
$$




\section{S.Krishnakumar and C.Elango}

$$
\begin{aligned}
& \mu \mathrm{P}(1, \mathrm{~N}, \mathrm{k})=\lambda \sum_{i=0}^{1} P(\mathrm{i}, \mathrm{N}-\mathrm{i}, \mathrm{k}), s+1 \leq k \leq S-1 \\
& (\lambda+\gamma p) \mathrm{P}(0,0, \mathrm{k})=\mu \mathrm{P}(1,0, \mathrm{k}+1), 0 \leq k \leq s \\
& (\lambda+\mathrm{j} \delta+\gamma p) \mathrm{P}(0, \mathrm{j}, \mathrm{k})=\mu \mathrm{P}(1, \mathrm{j}, \mathrm{k}+1), 1 \leq j \leq N, 1 \leq k \leq s \\
& (\lambda+\mu+\gamma p) \mathrm{P}(1,0, \mathrm{k})=\lambda P(0,0, \mathrm{k})+\delta \mathrm{P}(0,1, \mathrm{k}), 1 \leq k \leq s \\
& (\lambda+\mu+\gamma p) \mathrm{P}(1, \mathrm{j}, \mathrm{k})=\lambda \sum_{i=0}^{1} P(\mathrm{i}, \mathrm{j}-\mathrm{i}, \mathrm{k})+(\mathrm{j}+1) \delta \mathrm{P}(0, \mathrm{j}+1, \mathrm{k}), 1 \leq j \leq N-1,1 \leq k \leq s \\
& (\lambda+\gamma p) \mathrm{P}(0, \mathrm{j}, 0)=\mu \mathrm{P}(1, \mathrm{j}, 1)+\lambda \mathrm{P}(0, \mathrm{j}-1,0), 1 \leq j \leq N-1 \\
& \gamma p \mathrm{P}(0, \mathrm{~N}, 0)=\lambda P(0, N-1,0)+\mu \mathrm{P}(1, \mathrm{~N}, 1)
\end{aligned}
$$

Together with the above set of equations, the total probability condition

$$
\sum_{(\mathrm{i}, j, \mathrm{k}) \in E} P^{\pi}(\mathrm{i}, \mathrm{j}, \mathrm{k})=1
$$

gives steady state probabilities $\left\{\mathrm{P}^{\pi}(\mathrm{i}, \mathrm{j}, \mathrm{k}),(\mathrm{i}, \mathrm{j}, \mathrm{k}) \in \mathrm{E}\right\}$ uniquely.

\subsection{System Performance Measures}

The average inventory level in the system is given by

$$
\bar{I}^{\pi}=\sum_{i=0,1} \sum_{k=1}^{S} k \sum_{j=0}^{N} P^{\pi}(\mathrm{i}, \mathrm{j}, \mathrm{k}) .
$$

Mean waiting time in the orbit is given by

$$
\bar{W}^{\pi}=\sum_{i=0,1} \sum_{j=1}^{N} \frac{(\lambda+j \delta)}{\mu} \sum_{k=1}^{S} P^{\pi}(\mathrm{i}, \mathrm{j}, \mathrm{k}) .
$$

The reorder rate is given by

$$
\alpha_{a}^{\pi}=\sum_{i=0,1} \sum_{j=0}^{N} \sum_{k=0}^{s} \gamma P^{\pi}(\mathrm{i}, \mathrm{j}, \mathrm{k}) .
$$

The service completion rate is given by

$$
\alpha_{b}^{\pi}=\mu \sum_{i=0,1} \sum_{j=1}^{N} \sum_{k=1}^{S} P^{\pi}(\mathrm{i}, \mathrm{j}, \mathrm{k}) .
$$

Now the long run expected cost rate is given by

$$
\begin{aligned}
C^{\pi}= & h \sum_{i=0,1} \sum_{k=1}^{S} k \sum_{j=0}^{N} P^{\pi}(\mathrm{i}, \mathrm{j}, \mathrm{k})+c_{1} \sum_{i=0,1} \sum_{j=1}^{N} \frac{(\lambda+j \delta)}{\mu} \sum_{k=1}^{S} P^{\pi}(\mathrm{i}, \mathrm{j}, \mathrm{k}) \\
& +c_{2} \sum_{i=0,1} \sum_{j=0}^{N} \sum_{k=1}^{S} \gamma P^{\pi}(\mathrm{i}, \mathrm{j}, \mathrm{k})+\beta \mu \sum_{i=0,1} \sum_{j=1}^{N} \sum_{k=1}^{S} P^{\pi}(\mathrm{i}, \mathrm{j}, \mathrm{k})
\end{aligned}
$$


Inventory Control in Retrial Service Facility System- Semi Markov Decision Process

\section{Linear programming problem}

\subsection{Formulation of LPP}

In this section we propose a LPP model within a MDP framework. First we define the variables, $\mathrm{D}(\mathrm{i}, \mathrm{j}, \mathrm{k}, \mathrm{a})$ as a conditional probability expression

$\mathrm{D}(\mathrm{i}, \mathrm{j}, \mathrm{k}, \mathrm{a})=\operatorname{Pr}\{$ decision is a $\mid$ state is $(\mathrm{i}, \mathrm{j}, \mathrm{k})\}$.

Since $0 \leq D(i, j, k, a) \leq 1$, this is compatible with the deterministic time invariant

Markovian policies. Here, the Semi-Markovian decision problem can be formulated as a linear programming problem. Hence,

$0 \leq \mathrm{D}(\mathrm{i}, \mathrm{j}, \mathrm{k}, \mathrm{a}) \leq 1$ and $\sum_{a \in A=\{0,1,2\}} D(i, j, k, a)=1, \mathrm{i}=0,1 ; 0 \leq \mathrm{j} \leq \mathrm{N} ; 0 \leq \mathrm{k} \leq \mathrm{M}$.

For the reformulation of the MDP as LPP, we define another variable $y(i, j, k, a)$ as follows.

$y(i, j, k, a)=\mathrm{D}(i, j, k, a) \mathrm{P}^{\pi}(i, j, k)$.

From the above definition of the transition probabilities

$$
P^{\pi}(\mathrm{i}, \mathrm{j}, \mathrm{k})=\sum_{a \in A} y(i, j, k, a),(\mathrm{i}, \mathrm{j}, \mathrm{k}) \in \mathrm{E}, a \in \mathrm{A}=\{0,1,2\}
$$

Expressing $P^{\pi}(\mathrm{i}, \mathrm{j}, \mathrm{k})$ in terms of $y(\mathrm{i}, \mathrm{j}, \mathrm{k}, \mathrm{a})$, the expected total cost rate function (24) is obtained and the LPP formulation is of the form

Minimize

$$
\begin{gathered}
C^{\pi}=h \sum_{a \in A=\{0,1,2\}} \sum_{i=0,1} \sum_{k=1}^{S} k \sum_{j=0}^{N} P^{\pi}(\mathrm{i}, \mathrm{j}, \mathrm{k}, \mathrm{a})+c_{1} \sum_{a \in A=\{0,1,2\}} \sum_{i=0,1} \sum_{j=1}^{N} \frac{(\lambda+\mathrm{j} \delta)}{\mu} \sum_{k=1}^{S} P^{\pi}(\mathrm{i}, \mathrm{j}, \mathrm{k}, \mathrm{a}) \\
+c_{2}\left(\sum_{a \in A=\{0\}} \sum_{i=0,1} \sum_{j=0}^{N} \sum_{k=1}^{S} \gamma(1-p) P^{\pi}(\mathrm{i}, \mathrm{j}, \mathrm{k}, \mathrm{a})+\sum_{a \in A=\{1,2\}} \sum_{i=0,1} \sum_{j=0}^{N} \sum_{k=1}^{S} \gamma p P^{\pi}(\mathrm{i}, \mathrm{j}, \mathrm{k}, \mathrm{a})\right) \\
+\beta \mu \sum_{a \in A=\{0,1,2\}} \sum_{i=0,1} \sum_{j=1}^{N} \sum_{k=1}^{S} P^{\pi}(\mathrm{i}, \mathrm{j}, \mathrm{k}, \mathrm{a}),
\end{gathered}
$$

subject to the constraints,

(1) $y(i, j, k, a) \geq 0,(\mathrm{i}, \mathrm{j}, \mathrm{k}) \in \mathrm{E}, a \in \mathrm{A}_{l}, l=0,1,2$

(2) $\sum_{l=0}^{2} \sum_{(\mathrm{i}, \mathrm{j}, \mathrm{k}) \in \mathrm{E}_{l}} \sum_{a \in A_{l}} y(\mathrm{i}, \mathrm{j}, \mathrm{k}, \mathrm{a})=1$,

and the balance equations (2) - (18) are obtained by replacing

$P^{\pi}(\mathrm{i}, \mathrm{j}, \mathrm{k})$ by $\sum_{a \in A} y(\mathrm{i}, \mathrm{j}, \mathrm{k}, \mathrm{a})$.

Lemma 4.2. The optimal solution of the above Linear Programming Problem yields a deterministic policy.

Proof: From the equations

$y(\mathrm{i}, \mathrm{j}, \mathrm{k}, \mathrm{a})=\mathrm{D}(\mathrm{i}, \mathrm{j}, \mathrm{k}, \mathrm{a}) \mathrm{P}^{\pi}(\mathrm{i}, \mathrm{j}, \mathrm{k})$

and

$P^{\pi}(\mathrm{i}, \mathrm{j}, \mathrm{k})=\sum_{a \in A} y(\mathrm{i}, \mathrm{j}, \mathrm{k}, \mathrm{a}),(\mathrm{i}, \mathrm{j}, \mathrm{k}) \in \mathrm{E}$.

Since the decision problem is completely ergodic every basic feasible solution to the 


\section{S.Krishnakumar and C.Elango}

above linear programming problem has the property that for each $(\mathrm{i}, \mathrm{j}, \mathrm{k}) \in \mathrm{E}, y(\mathrm{i}, \mathrm{j}, \mathrm{k}, \mathrm{a})>0$ for every $\mathrm{a} \in \mathrm{A}$.

\section{Numerical illustration and discussion}

In this section we consider a service facility system maintaining inventory to illustrate the stochastic model described in section 4, through numerical examples. We have implemented TORA software to solve LPP by simplex algorithm.

Consider the MDP problem with the following parameters:

$\mathrm{S}=3, \mathrm{~s}=1, \mathrm{~N}=4, \lambda=2, \mu=3, \gamma=4, \delta=3, \mathrm{p}=0.8, \mathrm{~h}=0.1, \mathrm{c}_{\mathrm{j}}=2 \mathrm{j} ; \mathrm{j}=1,2, \beta=2$

The optimum cost for the system is $C=24.634$ and Optimal ordering policy for the proposed system is given in the table:

\begin{tabular}{|c|c|c|c|c|c|c|c|c|}
\hline$\{\mathrm{X}(\mathrm{t}), \mathrm{N}(\mathrm{t}), \mathrm{I}(\mathrm{t})\}$ & $(0,0,3)$ & $(0,1,3)$ & $(0,2,3)$ & $(0,3,3)$ & $(1,0,3)$ & $(1,1,3)$ & $(1,2,3)$ & $(1,3,3)$ \\
\hline Action & 0 & 0 & 0 & 0 & 0 & 0 & 0 & 0 \\
\hline$\{\mathrm{X}(\mathrm{t}), \mathrm{N}(\mathrm{t}), \mathrm{I}(\mathrm{t})\}$ & $(0,0,2)$ & $(0,1,2)$ & $(0,2,2)$ & $(0,3,2)$ & $(1,0,2)$ & $(1,1,2)$ & $(1,2,2)$ & $(1,3,2)$ \\
\hline Action & 0 & 0 & 0 & 0 & 0 & 0 & 0 & 0 \\
\hline$\{\mathrm{X}(\mathrm{t}), \mathrm{N}(\mathrm{t}), \mathrm{I}(\mathrm{t})\}$ & $(0,0,1)$ & $(0,1,1)$ & $(0,2,1)$ & $(0,3,1)$ & $(1,0,1)$ & $(1,1,1)$ & $(1,2,1)$ & $(1,3,1)$ \\
\hline Action & 0 & 0 & 0 & 0 & 0 & 0 & 0 & 1 \\
\hline$\{\mathrm{X}(\mathrm{t}), \mathrm{N}(\mathrm{t}), \mathrm{I}(\mathrm{t})\}$ & $(0,0,0)$ & $(0,1,0)$ & $(0,2,0)$ & $(0,3,0)$ & & & & \\
\hline Action & 2 & 2 & 2 & 2 & & & & \\
\hline
\end{tabular}

That is whenever the inventory level reaches the reorder level $s(>0)$ the optimal decision is to refill the inventory with $\mathrm{Q}=\mathrm{S}$-s items.

\section{Conclusion}

Analysis of inventory control at service facility is fairly recent system study. In most of previous works optimal ordering policies or system performance measures are determined. We approached the problem in new style using Semi-Markov Decision Process to control optimally the inventory replenishment. The optimum control policy to be employed is found using linear programming method so that the long-run expected cost rate is minimized. In future we like to extend this model to multi server-retrial Service Facility system with inventory maintenance.

Acknowledgement. The authors feel humble in acknowledging the HOD of the department of Mathematics, the Principal and Management providing conducive atmosphere in the campus and department to do continuous research in Mathematical Sciences.

\section{REFERENCES}

1. D.Arivudainambi, I.Averbakh and O.Berman, Stationary analysis of a single server retrial queue with priority and vacation, International Journal of Operational Research, 5 (2009) 26 - 47.

2. J.R.Artalejo and A.Gomez-Corral, Retrial Queuing Systems: A Computational Approach, Springer, Berlin, (2008).

3. J.R.Artalejo, and M.J.Lopez-Herrero, On the busy period of the $\mathrm{M} / \mathrm{G} / 1$ retrial queue, Naval Research Logistics, 47 (2000) 115 - 127.

4. J.R.Artalejo and M.J.Lopez-Herrero, On the single server retrial queue with balking, Informs, 38 (2000) 33 - 50. 
Inventory Control in Retrial Service Facility System- Semi Markov Decision Process

5. J.R.Artalejo, V.Rajagopalan and R.Sivasamy, On finite Markovian queues with repeated attempts, Investigación Operativa., 9 (2000) 83 - 94.

6. V.I.Dragieva, A finite source retrial queue: number of retrials, Communications in Statistics - Theory and Methods, 42 (2013) 812-829.

7. A.N.Dudin, R.Manzo and R.Piscopo, Single server retrial queue with group admission of customers, Computers \& Operations Research, 61 (2015) 89-99.

8. A.Elcan, Asymptotic bounds for an optimal state-dependent retrial rate of the $M / M / 1$ queue with returning customers, Mathematical and Computer Modelling, 30 (1999) 129-140.

9. G.I.Falin and J.G.C.Templeton, Retrial Queues, Chapman and Hall, London (1997).

10. Henk C. Tijms, A First Course in Stochastic Models, John Wiley \& Sons Inc., (2003).

11. A.Krishnamoorthy and K.P.Jose, An $(\mathrm{s}, \mathrm{S})$ inventory system with positive lead time, loss and retrial of customers, Stochastic Modelling and Applications, 8(2) (2005) 5671.

12. A.Krishnamoorthy and K.P.Jose, Comparison of inventory systems with service positive lead time, less and Retrial of customers, Journal of Applied Mathematics and Stochastic Analysis, (2007) doi:10.1155/2007/37848.

13. M.Paul, B.Sivakumar and G.Arivarignan, Service facility inventory system with impatient customers, International Journal of Mathematics, Game Theory and Algebra, 15(4) (2006) 355-367.

14. M.L.Puterman, Markov Decision Processes: Discrete Stochastic Dynamic Programming, Wiley Inderscience Publications Inc., (1994).

15. M.Schwarz, C.Sauer, H.Daduna, R.Kulik and R.Szekli, M /M /1 queueing system with inventory, Queueing Systems, Theory Appl., 1(54) (2006) 55-78. 